\title{
Electronic word-of-mouth communities from the perspective of social network analysis
}

\author{
F.J. Arenas-Márquez ${ }^{\mathrm{a}}$, M.R. Martínez-Torres ${ }^{\mathrm{a} *}$ and S.L. Toral ${ }^{\mathrm{b}}$ \\ ${ }^{a}$ Facultad de Turismo y Finanzas, University of Seville, Avda. San Francisco Javier s/n, 41018 Sevilla, Spain; \\ ${ }^{b}$ E. S. Ingenieros, University of Seville, Avda. Camino de los Descubrimientos s/n, 41092 Sevilla, Spain
}

\begin{abstract}
This paper is focused on the identification of influencers that can have an important impact over the decision-making of other users. For this purpose, a popular electronic word-of-mouth community like Ciao.com has been modelled as a social network. Using social network analysis techniques, the existence of influencers is justified by the power law distribution of user participation, and then they are identified using their topological features within the social network. The obtained results reveal that influencers are not determined by the number of performed reviews, but by the variety or scope of their performed reviews and their central position in the consumer network. The main contribution of this research is the identification of influencers based on the participation features of community users. As a difference to other studies, results are not based on surveys or opinions, but on the trace users leave when they post opinions, comments or scores.
\end{abstract}

Keywords: word of mouth; virtual communities; social network analysis; centrality; clustering coefficient

\section{Introduction}

The Internet offers consumers access to a large amount of information on a wide range of products and brands, thus enabling prices and qualities to be compared as well as the interaction with companies and other consumers (Hennig-Thurau and Walsh 2003; Khammash and Griffiths 2011). Additionally, the ongoing growth of electronic commerce is encouraging consumers to produce a huge amount of information that influences other consumers (Chatterjee 2001; Lee, Park, and Han 2011).

In this context, there is a rise in the number of websites where consumers can read and write online product reviews, sharing their opinions on different products. Some of these websites focus on a specific brand. It is also usual to find online retailers creating online communities where their customers can express their opinions (e.g. amazon.com, bestbuy.com and barnesandnoble.com). Finally, others have taken the form of web-based consumer-opinion platforms that allow users to review and comment different brands and types of products, attracting the participation of a high number of consumers (Jeppesen and Molin 2003). Some of the more well-known platforms are

\footnotetext{
*Corresponding author. Email: rmtorres@us.es
} 
epinions.com, dooyoo.com, cnet.com and ciao.com. All of them receive more than one hundred thousand visits per day. In the case of Ciao, it includes more than 1 million registered users and reviews on 1.4 million products.

Instead of being directed to small consumer groups with experience in specific areas, these consumer-opinion platforms provide information related to multiple consumer areas and sectors (Hennig-Thurau et al. 2004). Among other aspects, the online product reviews which can be found on these sites usually include a general product rating (e.g. in the form of stars), the specific scoring of certain attributes which vary depending on the product type analysed, key phrases (pros and cons) related to the product's perceived strengths and weaknesses, and the full text with all the comments and scores that the reviewer is willing to leave.

A social network is a set of people or groups of people with some pattern of contacts or interactions between them (Newman 2003; Scott 2000). According to this definition, consumer-opinion platforms allow consumers to develop social networks as they provide tools and mechanisms to facilitate interactions. Thus, registered users in consumer-opinion platforms are usually enabled to vote on helpfulness of product reviews and post their own comments about them. In addition, many consumer-opinion platforms (e.g. epinions.com, ciao.com) allow members to add other members who share their preferences and criteria in assessing products to their web trust network. The reviews written by members of the trust network appear at the top of the review page of a product. Therefore, this tool helps members to distinguish valuable information sources from less valuable ones (Ku, Wei, and Hsiao 2012).

The importance of word-of-mouth (WOM) is widely accepted in traditional marketing research (Cheung, Lee, and Rabjohn 2008; Lee, Park, and Han 2008). WOM consists of informal communications directed at other consumers about the ownership, usage or characteristics of particular goods and services and/or their sellers (Westbrook 1987). It is usually considered to be a very effective marketing tool with major repercussions on consumer behaviour (Khammash and Griffiths 2011; Phelps et al. 2004) and an impact on attitude-forming and decision-making, reducing the risk associated with these decisions (Cheung, Lee, and Rabjohnc 2008). In view of the above, consumer-opinion platforms provide an alternative and effective marketing channel to firms, in the form of electronic WOM (eWOM), which does not require huge investments in advertising (Ku, Wei, and Hsiao 2012; Trusov, Bucklin, and Pauwels 2009). Therefore, these large-scale online communities have redefined traditional WOM social networks by allowing consumers to share their opinions with other members very easily (Chen, Dhanasobhon, and Smith 2008).

Given the growing importance of eWOM and consumer-opinion platforms, the way these virtual communities work needs to be analysed as well as their structure and the behaviour of their users. In this analysis, the identification of possible influencers is of great interest to business given the importance and impact that their reviews can cause on other consumers' purchase intent. The role of the in?uencer is to evaluate and communicate assessments of products and services, which may infuence future purchase decisions (Ferguson and Johnston 2011). The literature on WOM marketing describes multiple attributes of influencers: they have multiple interests, are early adopters in markets, are trusted by other consumers and have a large social network (Keller and Berry 2003; Kiss and Bichler 2008). Influencers may exercise a major impact on the opinions of other consumers with their broad experiences and deep knowledge in their fields (Cho, Hwang, and Lee 2012; Kim and Tran 2013).

Most earlier studies in the eWOM field usually focus on aspects such as the influence that product reviews can have on purchase intent or on consumers' motives for reading or writing these reviews (Chen, Wu, and Yoon 2004; Cheung et al. 2009; Dellarocas, Zhang, and Awad 2007; Gu, 
Tang, and Whinston 2013). However, there has been very little examination of consumer-opinion platforms' internal structures. This paper is a contribution to the field and uses social network analysis (SNA) tools in a study of ciao.com, one of the most popular consumer-opinion platforms. More specifically, this paper analyses the structure of the user network and determines the main antecedents of influencers from a topological point of view.

The remainder of this paper is organised as follows: Section 2 reviews the related literature about eWOM. Section 3 proposes the hypotheses of this study. Section 4 details the case study and the methodology to validate the proposed hypotheses. Section 5 describes the obtained results followed by their discussion. Finally, Section 6 summarises the conclusions of this work.

\section{Literature review}

Consumer-opinion platforms offer consumers the access to wide amounts of information on opinions and recommendations on sellers and products from experienced consumers. Researchers often refer to this online consumer sharing activity as eWOM (Cheung et al. 2009). HenningThurau et al. (2004) define eWOM communication as any positive or negative statement made by customers - potential, real or former - about a product or company, which is made available to other people via the Internet. This definition and its theoretical categorisation are widespread in the literature (Cheung et al. 2009; Jeong and Jang 2011; Pan and Chiou 2011; Smith, Fischer, and Yongjian 2012; Vilpponen, Winter, and Sundqvist 2006). eWOM exhibits important differences with respect to traditional WOM communications. First, eWOM communication is frequently asynchronous, so sender and receiver are separated by both space and time (Jeong and Jang 2011; Steffes and Burgee 2009). Second, positive and negative consumer reviews are presented at the same time in the same online place (Chatterjee 2001). Third, online consumer reviews can be collected and analysed, as a difference to traditional WOM communications that take place in private conversations which are difficult to observe (Kiss and Bichler 2008) and require the use of surveys instead of direct observations (Bowman and Narayandas 2001). Online communities enable direct observations as the information is publicly available. For instance, the quantity and persistence of eWOM communications have been used to analyse how online consumer reviews impact on sales (Chevalier and Mayzlin 2006; Dellarocas, Awad, and Zhang 2005).

Many studies on eWOM focus on the influence that product reviews could have on consumption decisions and sales in different sectors (Amblee and Bui 2007; Antweiler and Frank 2004; Chen, Wu, and Yoon 2004; Chen, Dhanasobhon, and Smith (2008); Chevalier and Mayzlin 2006; Chintagunta, Gopinath, and Venkataraman 2010; Dellarocas, Zhang, and Awad 2007; Dhar and Chang 2009; Duan, Gu, and Whinston 2008; Forman, Ghose, and Wiesenfeld 2008; Gu, Tang, and Whinston 2013; Lee, Park, and Han 2008; Liu 2006; Tumarkin and Whitelaw 2001; Yang and Mai 2010). Papers of this type often measure the impact of a range of the dimensions of online reviews, mainly the volume (the number of reviews received by a product) and the valence (the positive or negative nature of the review).

With respect to volume, Dhar and Chang (2009) highlight the importance of the number of online reviews in the music sales sector, which appears to be positively correlated with the number of blog posts about an album. Amblee and Bui (2007) arrive at a similar conclusion about digital short books on Amazon.com. In the same virtual store, Chen, Wu, and Yoon (2004) empirically investigate the impacts of recommendations and consumer feedback and conclude that the number of consumer reviews is positively associated with book sales. Studies by Duan, Gu, and Whinston (2008) and Liu (2006), whose data were collected from websites such as Variety.com or Yahoo Movies show that the volume of online posting can raise awareness of a product among potential 
buyers and increase box office revenue. In the finance field, studies by Tumarkin and Whitelaw (2001) and Antweiler and Frank (2004) find that the volume of postings on Internet financial forums affects stock prices and the volume of transactions.

Other studies highlight the influence of the valence on consumer behaviour. Chevalier and Mayzlin (2006) find that an improvement in the reviews of any given book led to an increase in relative sales on Amazon.com, with negative reviews having a greater impact than positive reviews. Yang and Mai (2010) arrive at the same conclusion in the online video game market. Dellarocas, Zhang, and Awad (2007) show that, apart from volume, the average valence of online user reviews provides a valid framework for making predictions about future movie sales. Meanwhile, Chintagunta, Gopinath, and Venkataraman (2010) find that the valence is the main driver of box office performance in the same market. Using panel data collected from Amazon.com, Gu, Tang, and Whinston (2013) show that positive reviews improve the sales of popular products more than those of niche products, while negative reviews harm niche products more than popular products. In a similar line, Lee, Park, and Han (2008) investigate the effects of negative online consumer reviews on consumer attitude to $\mathrm{mp} 3$ multimedia players, concluding that consumer's attitudes become less favourable as the proportion of negative online reviews increases.

The quality of the reviews and the reputation of the reviewers are specifically considered to be important factors affecting purchase decisions by some researchers who are more focused on the impact triggered in consumers by the perceived usefulness and credibility of the information. Forman, Ghose, and Wiesenfeld (2008) use the online helpfulness vote on Amazon.com as an indicator of the quality of the reviews and finds that consumers do not only take into account the volume and the valence of the reviews, but also their quality. Using consumer reviews for books, Chen, Dhanasobhon, and Smith (2008) mine data taken from the same site and find that reviews with a high proportion of helpful votes (higher quality reviews) have a stronger impact on consumer purchase decisions and are associated with increasing sales.

Although a wide variety of aspects of online consumer reviews have been studied, the literature on eWOM shows that the networks formed by the consumers who are involved in them have only been analysed to a very limited extent. Given the influence that eWOM and consumer-opinion platforms have on purchasing behaviour, the structures of these virtual communities and user behaviour need to be examined. However, research on the internal structures of consumer-opinion platforms is practically non-existent. In fact, at the time of writing this paper, practically only the recent study by Ku, Wei, and Hsiao (2012) using data from Epinions.com can be highlighted. These authors seek to identify reputable reviewers in consumer-opinion communities according to the web trust network built up between its members and their review behaviour.

\section{Hypotheses}

Power-law distribution means that the majority of the nodes only have a small number of links while only a small fraction of nodes have a large number of links (Barabási 2001). Therefore, power laws characterise the transition from disorder to order and the presence of self-organising mechanisms (Abu-Rahmeh 2009). This is the case of product reviews, which tend to focus on a reduced group of top products. Additionally, if the internal structure of the major consumeropinion platforms can be modelled as a scale-free network, it will also be possible to identify those users who play the role of influencers (Breschi et al. 2009; Martínez-Torres et al. 2010). 
By using SNA, it is possible to determine the distribution followed by the product and user networks. Therefore, we hypothesise:

$H 1$ : Product reviews in online consumer-opinion platforms follow a power law distribution.

$H 2$ : User participation in online consumer-opinion platforms follow a power law distribution.

One major challenge of consumer-opinion platforms consists of determining the characteristics that are more suitable for identifying an influencer within the platform. Many virtual stores (e.g. Amazon.com) and consumer-opinion platforms (e.g. Ciao.com) have rating systems that enable consumers to vote on whether posted reviews have been helpful to them (Chen, Dhanasobhon, and Smith 2008). The number or proportion of helpful votes that a review receives can serve as an indicator for its content quality for other consumers. Also, a high number of reviews with a higher number of helpful votes can be an indicator of the reviewer's quality (Amazon.com uses this criterion) and, in the final instance, of his/her reputation. It therefore seems evident that the reputation of the reviewer, measured according to the ratings that other consumers give his/her reviews, is, a priori, a good indicator for characterising possible influencers.

Reviewer's exposure in the online review community is another magnitude that could also be important for this. It can be measured by how many times a reviewer posts reviews on an online community website. Hu, Liu, and Zhang (2008) state that apart from being influenced by higher quality reviewers, consumers pay more attention to reviewers with high exposure. Likewise, reviews written by lower exposure reviewers might be less likely to change consumers' uncertainties and transaction costs for buying a product.

In the context of eWOM communication, online reviews are often shared by unknown individuals (Cheung and Thadani 2012) and because of this some studies suggest that this might affect their credibility (Park and Lee 2009; Park, Lee, and Han 2007). It is also common to find concerns about the possible fraudulent involvement on the consumer platform of the manufacturers themselves, writing reviews of their own products. However, it is usual to require that reviews must be posted by registered users. This fact contributes to raising consumers' perceived credibility with the consequent impact on their purchases (Forman, Ghose, and Wiesenfeld 2008).

The study of the topological features of the user network within the consumer platform (which cannot be easily manipulated) can be used to identify influencers (our dependent variable). More specifically, influencers should occupy a more central position in the network formed by registered users in the online consumer-opinion platform. Accordingly, we propose the following hypothesis:

$H 3 a$ : Influencers in online consumer-opinion platforms can be identified by means of their centrality measures.

$H 3 b$ : Influencers in online consumer-opinion platforms occupy a central position in the registered users' network.

Another important aspect related to the reputation of a reviewer in an online consumer-opinion platform is his/her expertise with regard to the reviewed products. The expertise level of a reviewer is likely manifested in his or her review behaviour and probably a high-level reviewer is a very active contributor in a certain domain or product category $(\mathrm{Ku}, \mathrm{Wei}$, and Hsiao 2012; Martínez-Torres and Diaz-Fernandez 2013). This active contribution should be reflected not only on the number of reviews, but also on a wide range of products (i.e. products of different brands, technical features or benefits) that the influencer is able to review. Thus, we propose the following hypothesis: 
$H 4$ : Influencers in online consumer-opinion platforms review a wide variety of products in the same product category.

\section{Case study and methodology}

Ciao.com is an online opinion portal where registered users can critically review and rate products. It is one of the most popular consumer networks and receives more than 20,000 page views per day. Final consumers can benefit from reviews by other users and price information from online shops. However, making reviews requires to become a membership (available free of charge). Registered users can write comments and score products using qualitative ratings that correspond to numerical values (currently, the website contains over 2,000,000 consumer reviews). Their review can also be scored by other members.

Ciao website is structured through categories of products and services. Among the huge sets of categories, this research has considered mobile phones as they include a wide variety of items receiving a variable number of reviews. A specific web crawler has been developed to extract data from this category (Martínez-Torres 2014). A web crawler is a software program that follows the link structure on the web, retrieving the desired information. In this case, the web crawler was programmed to follow the link structure within the mobile phones category. Extracted indicators are detailed in Table 1.

Using the designed web crawler, 1005 different mobile phones were analysed at ciao.com. Up to 17,044 reviews were performed by 13,644 different registered users. For each review, the alias of the registered user, the score of the reviewed item and the received score of the review (user, score and rev_rating of Table 1) were stored.

The proposed methodology consists of modelling communities as social networks. Basically, a social network is a graph where nodes represent actors and edges represent the interactions among them. The main advantage of using SNA techniques is that several topological features of the nodes can be extracted as part of the global network. These features are related with their participation activity, and they can reveal patterns of behaviour of users within communities (Martínez-Torres 2013). For instance, the patterns of participation have already been used to analyse the structure of communities or to characterise those users occupying relevant positions (Sowe, Stamelos, and Angelis 2006; Toral, Martínez-Torres, and Barrero 2010). The main limitation is that SNA does not take into account the quality of posted ideas and comments, but their quantity. However, analysing the content of shared opinions one by one would be a high time-consuming task.

The collected information has been used to build a two-mode network, where nodes of the graph are divided into two sets: mobile phones and registered users that have reviewed them. Figure 1 shows the obtained two-mode network. Mobile phones are represented as black nodes while users are drawn as white nodes.

Table 1. List of indicators extracted from ciao website.

\begin{tabular}{ll}
\hline Indicators & \multicolumn{1}{c}{ Description } \\
\hline product & Name of the mobile phone \\
$\mathrm{n} \_$rev & Number of reviews \\
user & Alias of each registered user who has sent at least one review \\
score & Scores of mobile phone reviewed \\
rev_rating & Score of the review (by other members) \\
\hline
\end{tabular}




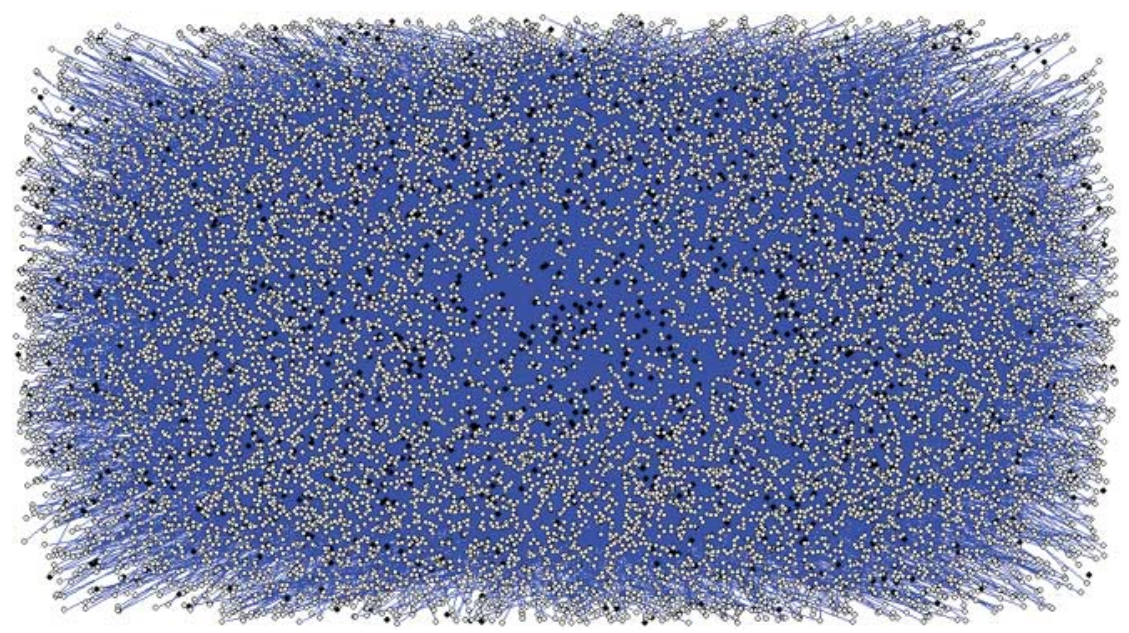

Figure 1. Two-mode network corresponding to mobile phone category at ciao.

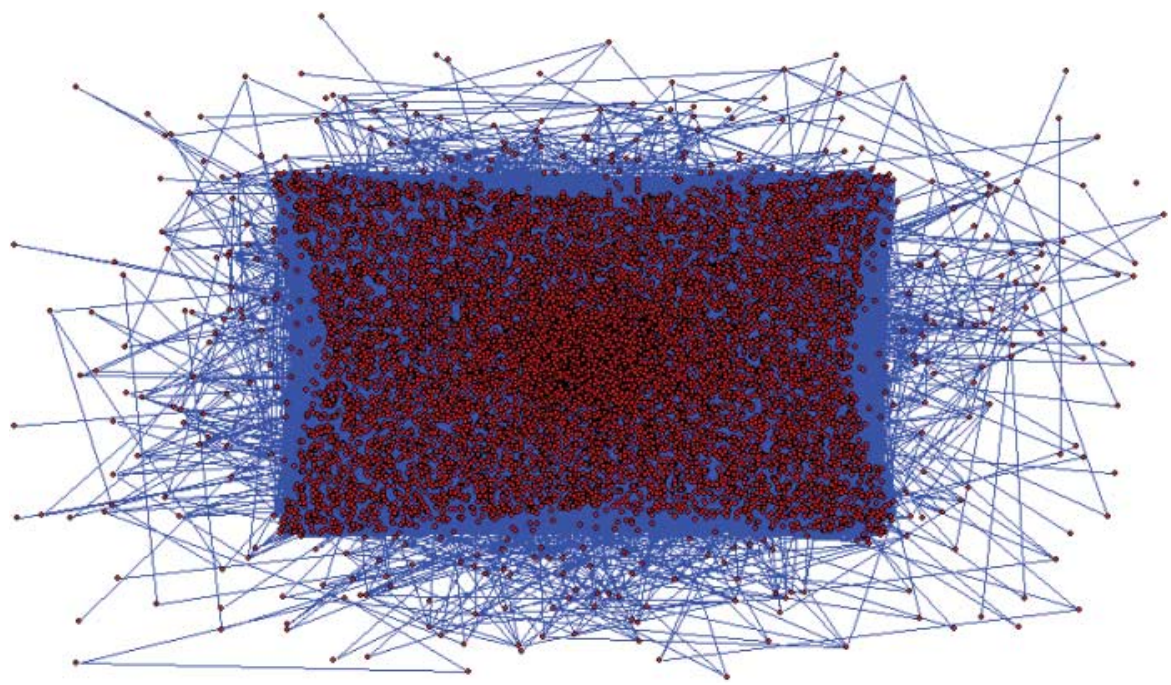

Figure 2. Network of users (one-mode network derived from Figure 1).

Two one-mode networks can be derived from the original two modes of Figure 1: the network of products and the network of users. As this research is focused on analysing eWOM communities, the network of users will be considered. This network is derived as follows: whenever two registered users have reviewed a mobile phone, an edge among them is set in the corresponding one-mode network. The network of users is detailed in Figure 2.

From a mathematical point of view, the network of users can be represented as an adjacency matrix $A$, where $a(i, j)=1$ if nodes $i$ and $j$ are connected and $a(i, j)=0$ otherwise. Several properties of the network can be computed using SNA tools: 
Size: The number of nodes represents the total number of products and users in case of Figure 1 (two-mode network) and the total number of registered users in case of Figure 2 (one-mode network).

Degree: The degree of a node is the number of edges associated with this node. In Figure 1, the degree of a black node (representing a mobile phone) is the number of received reviews, while the degree of a white node is the number of reviews a registered user has done. In Figure 2, the degree of a node is measuring the number of interactions between a particular node and the rest of the network.

Degree centrality: This definition considers that a node is more central as it is more connected with the rest of nodes. Mathematically, degree centrality of node $i$ is defined as

$$
C_{\mathrm{D}}(i)=\sum_{j=1}^{n} a_{i, j}
$$

Closeness centrality: It is a measurement of centrality based on the idea of distance among nodes. It is defined as the total distance between a node and the rest of nodes of the network. Therefore, those nodes closer to the rest of nodes have a high value of closeness centrality and they are said to occupy a more central position in the network. Mathematically, closeness centrality of a node can be computed using the definition of Wassermann and Faust (1994), which considers the size of the network.

$$
C_{\mathrm{C}}=\frac{(n-1)}{\sum_{j=1}^{n} d(i, j)},
$$

where $n$ is the size of the network and $d_{(i, j)}$ is the minimum length of a path connecting nodes $i$ and $j$ (the shortest path connecting two nodes is called geodesic).

Betweenness centrality: It is an alternative measure of centrality based on the idea that a node occupies a more central position depending on the extent this node is performing an intermediary role in the communication network. Formally, the betweenness centrality of a node is defined as the proportion of all geodesics between pairs of other nodes that include this node. Mathematically, betweenness centrality can be computed using the following formula (Freemann 1977):

$$
C_{\mathrm{B}}=\frac{\sum_{i \neq j \neq l} g_{j l}(i)}{g_{j l}},
$$

where $g_{j l}(i)$ is the number of shortest paths connecting the two nodes $j$ and $l$ that contains node $i$.

Clustering coefficient: It measures whether the one-hop neighbours of a particular node interact with each other. Basically, the clustering coefficient is a measure of local cohesiveness through the neighbour interactions of a node. Mathematically, the clustering coefficient of a node $i$ is defined as twice the ratio between the number of edges $\left|e_{j l}\right|$, which connect the $k_{i}$ neighbours, divided by the total number of possible edges $k_{i}\left(k_{i}-1\right), N_{i}$ being the set of neighbours of node $i$, and $E$ the set of edges:

$$
C C_{i}=\frac{2\left|e_{j l}\right|}{k_{i}\left(k_{i}-1\right)}, \quad j, l \in N_{i}, e_{j l} \in E .
$$

\section{Results}

The degree distributions of the products and users in the two-mode network are illustrated in Figures 3 and 4, respectively. Both of them have been fitted to a power law distribution, where the 


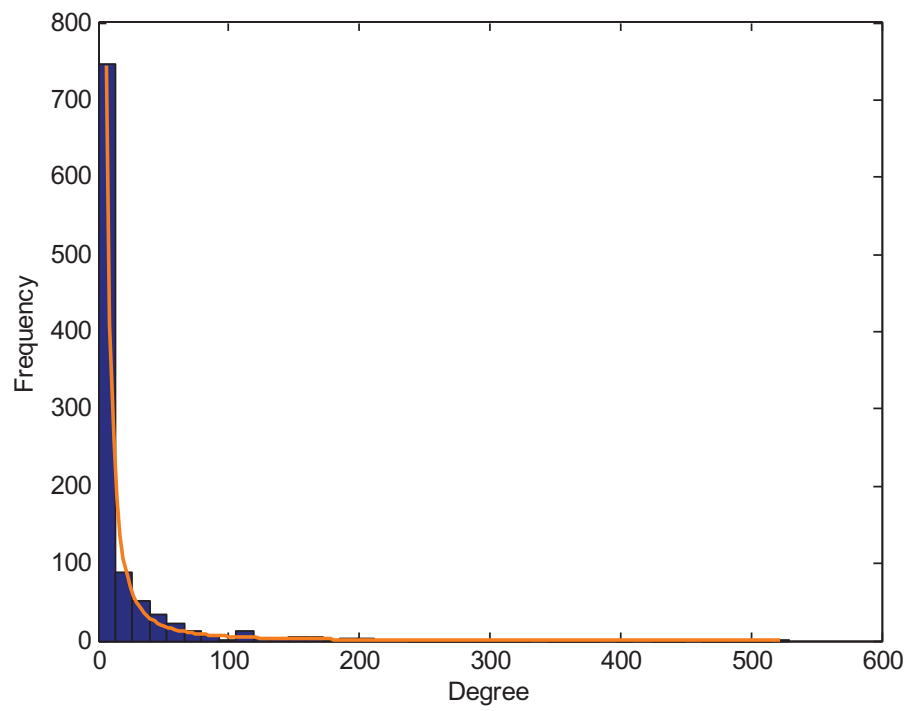

Figure 3. Degree distribution of products and power law fit.

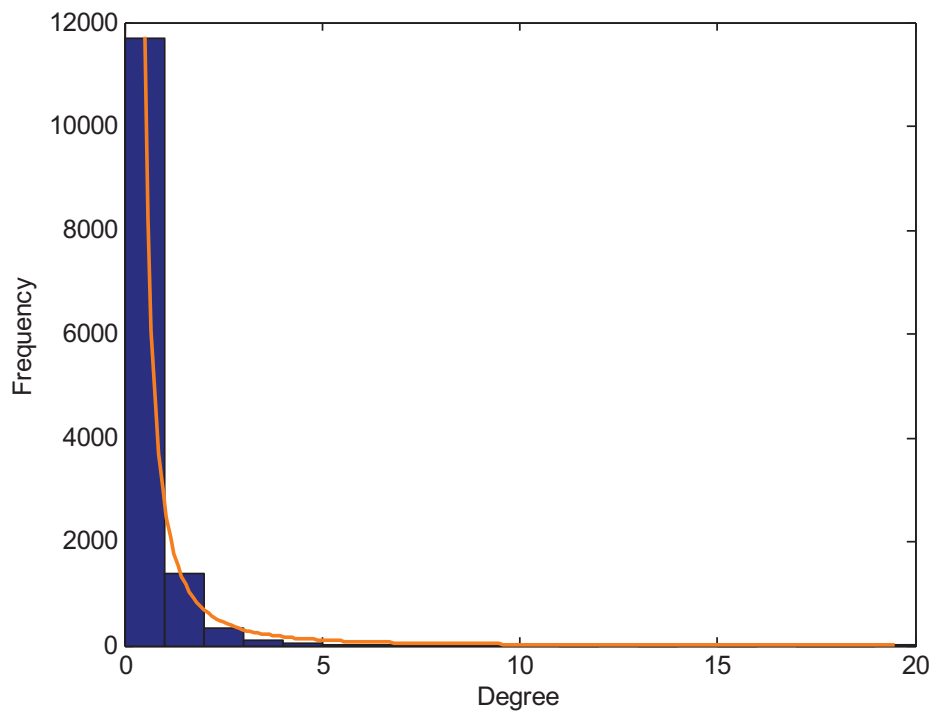

Figure 4. Degree distribution of users and power law fit.

probability of obtaining a certain frequency is given by the equation $C x^{-\alpha}, C$ being a normalisation constant and $\alpha$ the power law exponent.

The $\alpha$ coefficient was estimated according to the goodness-of-fit based method described in Clauset, Shalizi, and Newman (2007). The obtained result is $\alpha=2.29$ for the case of products and $\alpha=3.5$ for the case of users. The Kolmogorov-Smirnov test $D$ value for both networks are below the critical value given by $1.63 / N^{0.5}$. Therefore, the null hypothesis applies and both product reviews and user participation networks follow a power law distribution. Consequently, Hypotheses $H 1$ 
Table 2. Threshold values for the selection of influencers.

\begin{tabular}{lcc}
\hline Cases & Posted reviews & $\%$ users \\
\hline (a) & $\geq 2$ & 15.5 \\
(b) & $\geq 3$ & 4.4 \\
& Rev_rating & $\%$ users \\
(c) & $\geq 50$ & 12.3 \\
(d) & $\geq 60$ & 9.1 \\
(e) & $\geq 70$ & 6.0 \\
(f) & $\geq 80$ & 3.8 \\
(g) & $\geq 90$ & 3.0 \\
(h) & $\geq 100$ & 2.5 \\
\hline
\end{tabular}

and $H 2$ are confirmed. This finding shows that the internal structure of the consumer-opinion community can be modelled as a scale-free network where the majority of the links are associated with a small number of nodes.

With respect to Hypotheses $H 3$ and $H 4$, the analysis of the topological features of influencers requires first to define which users can be considered as such. Based on previous studies, the posting activity (exposure) of the reviewers and their reputation can be considered the two most important characteristics of influencers. The first one can be measured using the number of posted reviews on the consumer-opinion platform. Regarding the reputation of reviewers, it can be measured according to the ratings received from the rest of the community. Figure 4 shows that the $84.5 \%$ of users only post one review. Therefore, the threshold value to be considered as an influencer can be selected either as 2 (which corresponds to the $15.5 \%$ of users that sent at least two reviews) or 3 (which corresponds to the $4.4 \%$ of users that posted at least three reviews). The rating received from the rest of the community also follows a similar power law distribution. The different possible threshold values are shown in Table 2.

The dependent variable in this study is the condition of being an influencer which is determined by the thresholds in Table 2 . The eight cases of Table 2 were considered, and eight binary logistic regressions were performed using the topological properties of nodes (centrality measures) as independent variables.

Table 3 shows the results obtained for the eight logistic regressions, and Table 4 details the classification tables of influencers and non-influencers as well as the percentages of correct classification. The total percentage correct is high in all cases. Obviously, the percentage corresponding to correct classification of influencers is lower as they represent only a small fraction of community users. The Hosmer and Lemeshow test was not significant in all cases, so the predicted and observed probabilities match up.

The logistic regression results reveal that there is an almost null dependence, and in many cases not significant, of the degree of nodes. A high degree value of a node implies that this node is connected to many other nodes. According to the way the community has been modelled, this means that this user is posting reviews for popular products which in turn receive reviews from many other consumers. This result makes sense as most users typically post only one review and they usually write about popular products which are evaluated by many other similar users. On the other hand, the results also show a positive and significant dependence of influencers on closeness and betweenness centralities. The more central a node is in terms of distance and mediation, the higher the probability of being an influencer. Finally, it can be reported a negative but significant 
Table 3. Logistic regression results for the eight considered cases.

\begin{tabular}{|c|c|c|c|}
\hline Case & Variables & Logistic coefficient (standard error) & Wald \\
\hline \multirow[t]{5}{*}{ (a) } & Degree & $-0.003(0.000)$ & $32.803^{* * *}$ \\
\hline & Closeness & 30.628 (1.932) & $251.255^{* * *}$ \\
\hline & Betweenness & $7113.895(461.478)$ & $237.637^{* * *}$ \\
\hline & $\mathrm{CC}$ & $-12.600(0.413)$ & $929.461^{* * *}$ \\
\hline & Nagelkerke $R^{2}$ & 0.840 & \\
\hline \multirow[t]{5}{*}{ (b) } & Degree & $0.001(0.000)$ & $5.445^{*}$ \\
\hline & Closeness & $16.200(2.439)$ & $44.130^{* * *}$ \\
\hline & Betweenness & $1369.163(145.300)$ & $88.794 * * *$ \\
\hline & $\mathrm{CC}$ & $-9.597(0.459)$ & $436.375^{* * *}$ \\
\hline & Nagelkerke $R^{2}$ & 0.721 & \\
\hline \multirow[t]{5}{*}{ (c) } & Degree & $-0.002(0.000)$ & $19.756^{* * *}$ \\
\hline & Closeness & $22.756(1.716)$ & $175.895^{* * *}$ \\
\hline & Betweenness & $2204.314(195.039)$ & $127.733^{* * *}$ \\
\hline & $\mathrm{CC}$ & $-9.329(0.255)$ & $1342.689^{* * *}$ \\
\hline & Nagelkerke $R^{2}$ & 0.702 & \\
\hline \multirow[t]{5}{*}{ (d) } & Degree & $-0.001(0.000)$ & $3.901^{*}$ \\
\hline & Closeness & $17.231(1.517)$ & $129.000^{* * *}$ \\
\hline & Betweenness & $1100.862(137.632)$ & $63.977^{* * *}$ \\
\hline & $\mathrm{CC}$ & $-8.127(0.235)$ & $1198.723^{* * *}$ \\
\hline & Nagelkerke $R^{2}$ & 0.620 & \\
\hline \multirow[t]{5}{*}{ (e) } & Degree & $0.000(0.000)$ & 0.189 \\
\hline & Closeness & $14.010(1.650)$ & $72.127^{* * *}$ \\
\hline & Betweenness & $1020.512(122.133)$ & $69.818^{* * *}$ \\
\hline & $\mathrm{CC}$ & $-7.480(0.264)$ & $805.633^{* * *}$ \\
\hline & Nagelkerke $R^{2}$ & 0.597 & \\
\hline \multirow[t]{5}{*}{ (f) } & Degree & $0.000(0.000)$ & 0.012 \\
\hline & Closeness & $16.664(2.611)$ & $40.732^{* * *}$ \\
\hline & Betweenness & $1043.436(123.785)$ & $71.055^{* * *}$ \\
\hline & $\mathrm{CC}$ & $-8.562(0.398)$ & $462.481^{* * *}$ \\
\hline & Nagelkerke $R^{2}$ & 0.665 & \\
\hline \multirow[t]{5}{*}{ (g) } & Degree & $0.000(0.000)$ & 0.848 \\
\hline & Closeness & $17.177(3.140)$ & $29.924^{* * *}$ \\
\hline & Betweenness & 933.355 (117.366) & $63.243^{* * *}$ \\
\hline & $\mathrm{CC}$ & $-8.768(0.471)$ & $346.476^{* * *}$ \\
\hline & Nagelkerke $R^{2}$ & 0.675 & \\
\hline \multirow[t]{5}{*}{ (h) } & Degree & $0.000(0.000)$ & 0.360 \\
\hline & Closeness & 23.394 (3.812) & $37.651^{* * *}$ \\
\hline & Betweenness & 339.915 (80.079) & $18.018^{* * *}$ \\
\hline & $\mathrm{CC}$ & $-9.103(0.496)$ & $336.668^{* * *}$ \\
\hline & Nagelkerke $R^{2}$ & 0.630 & \\
\hline
\end{tabular}

dependence on the clustering coefficient. The clustering coefficient measures the ratio between the interactions of nodes located in one-hop neighbourhood of a given node and its degree. As the degree is not significant, this result can be interpreted as a low value in the numerator of the clustering coefficient, which in turn means influencers usually review a wide variety of products (e.g. mobile phones and smartphones from different manufacturers and with different features). 
Table 4. Classification matrices.

\begin{tabular}{|c|c|c|c|c|}
\hline \multirow[b]{2}{*}{ Case } & \multirow[b]{2}{*}{ Observed } & \multicolumn{2}{|c|}{ Estimated } & \multirow[b]{2}{*}{ Percentage correct } \\
\hline & & Non-influencers & Influencers & \\
\hline \multirow{3}{*}{ (a) } & Non-influencers & 12,037 & 67 & 99.4 \\
\hline & Influencers & 185 & 208 & 52.9 \\
\hline & Total percentage correct & & & 98.0 \\
\hline \multirow[t]{3}{*}{ (b) } & Non-influencers & 11,880 & 72 & 99.4 \\
\hline & Influencers & 207 & 338 & 62.0 \\
\hline & Total percentage correct & & & 97.8 \\
\hline \multirow[t]{3}{*}{ (c) } & Non-influencers & 10,619 & 313 & 97.1 \\
\hline & Influencers & 421 & 1144 & 73.1 \\
\hline & Total percentage correct & & & 94.1 \\
\hline \multirow[t]{3}{*}{ (d) } & Non-influencers & 11,007 & 316 & 97.2 \\
\hline & Influencers & 529 & 645 & 54.9 \\
\hline & Total percentage correct & & & 93.2 \\
\hline \multirow[t]{3}{*}{ (e) } & Non-influencers & 11,583 & 122 & 99.0 \\
\hline & Influencers & 400 & 392 & 49.5 \\
\hline & Total percentage correct & & & 95.8 \\
\hline \multirow[t]{3}{*}{ (f) } & Non-influencers & 11,922 & 79 & 99.3 \\
\hline & Influencers & 230 & 266 & 53.6 \\
\hline & Total percentage correct & & & 97.5 \\
\hline \multirow[t]{3}{*}{ (g) } & Non-influencers & 12,037 & 67 & 99.4 \\
\hline & Influencers & 185 & 208 & 52.9 \\
\hline & Total percentage correct & & & 98.0 \\
\hline \multirow[t]{3}{*}{ (h) } & Non-influencers & 12,123 & 55 & 99.5 \\
\hline & Influencers & 180 & 139 & 43.6 \\
\hline & Total percentage correct & & & 98.1 \\
\hline
\end{tabular}

In summary, the obtained results confirm that influencers can be identified by means of centrality measures such as closeness and betweenness centrality, and the clustering coefficient, which confirms Hypotheses $H 3 a$ and $H 3 b$. Furthermore, Hypothesis $H 4$ can also be accepted and it can be concluded that influencers exhibit a more comprehensive knowledge in the field of mobile phones than the rest of users and their reviews are based on a wider knowledge of this market.

\section{Conclusions and implications}

With the growth of electronic commerce, there is also an increase in the number of web-based consumer-opinion platforms that allow users to read and provide information related to multiple areas and sectors (Lee et al. 2006). These online consumer reviews have a major influence on decision-making processes of other consumers.

The literature on eWOM usually focuses on aspects such as the impact of different dimensions of online reviews (volume, valence, quality of the reviews, reputation of the reviewers, etc.) on purchase decisions and sales. However, there are very few studies that analyse the networks formed by the users of these consumer-opinion platforms. This study provides a new contribution to the existing literature and enables the distribution followed by the product and user networks in a well-known consumer-opinion platform (Ciao.com) to be reflected upon. SNA tools have been used to study the topological features of the reviewer network and identify influencers. 
The findings show that both product reviews and user participation networks follow a power law distribution which allows the users who play the role of influencers to be identified. The analysis of the results also reveals that influencers have a more central position in the user network and a significant dependence on centrality measures (such as closeness, betweenness and clustering coefficient). Finally, it can be concluded that influencers usually review a wider range of products (different brands or technical features) which reflect their greater expertise with regard to a certain field or product category.

This study has managerial implications for different aspects. Product reviews from the main consumer-opinion platforms let firms approach their customers (Lee 2007), uncover topics and trends that are relevant (Gamon et al. 2005) and improve their marketing campaigns or products accordingly (Wei et al. 2010). In this context, the identification of influencers is of great interest to businesses, given the impact that their reviews can cause on other consumers' purchase behaviour. As $\mathrm{Ku}$, Wei, and Hsiao (2012) state, firms should pay special attention to negative reviews from these users and take appropriate actions improving their products or services, otherwise negative eWOM could spread quickly through the influencers.

Furthermore, the identification of influencers enables viral marketing techniques which make use of the social network to stir up interest in certain products or brands. Viral marketing use consumer-to-consumer communications to disseminate information about a product, leading to more rapid and cost-effective adoption by the market (De Bruyn and Lilien 2008; Dobele et al. 2007). When executed effectively, these campaigns can create an instantaneous buzz in the promotion and distribution of products (Dobele et al. 2007). Viral marketing techniques work better when they focus on the influencers, as they have the ability to diffuse messages more quickly, credibly and efficiently through opinion websites (Kiss and Bichler 2008). Thus, both manufacturers and retailers can provide new products to influencers; the more positive their opinions and reviews of these products, the more likely they are to influence other consumers' purchase decision increasing sales.

Finally, given the importance of the number of reputable members for the success of consumeropinion platforms (Ku, Wei, and Hsiao 2012), firms that host sites such as Ciao.com should develop effective strategies to identify influencers, recognise their reputation explicitly and provide incentives to retain them. Research in appropriate mechanisms that reveal the reputation of reviewers who participate in the consumer-opinion platform becomes essential (Dellarocas 2003). These mechanisms should help consumers to attend the reviews written by more reputable reviewers.

\section{Acknowledgements}

This work has been supported by the Consejería de Economía, Innovación, Ciencia y Empleo (Research Project with reference P12-SEJ-328) and the Spanish Research Programme (Research Project with reference ECO2013-43856-R).

\section{Notes on contributors}

F.J. Arenas-Márquez is an Assistant Professor of Operations Management and Information Systems and Technologies at the University of Seville. His research involves e-business, Information Systems and development of interactive software for instruction in Business Administration. He has worked in numerous national and European projects related to this research lines and is author/co-author of different publications in this field. He has been research visitor at several universities (Nottingham, Glasgow, Edinburgh, Linköping and London Business School).

M.R. Martínez-Torres is an Associate Professor in Management and Business Administration at Business Administration and Marketing Department, University of Seville. Her main research interests include Intellectual Capital and Knowledge 
Management and Social Network Analysis. She has co-authored articles in many leading academic and professional journals, including Information and Management; IEEE Transactions on Education; Computers \& Education and Behaviour and Information Technology.

S.L. Toral is an Associate Professor in Digital Electronic Systems at the Department of Electronic Engineering, University of Seville. His main research interests include Open Source Software projects, Open Innovation and Social Network Analysis.

\section{References}

Abu-Rahmeh, O. 2009. A statistical mechanics approach for an effective, scalable, and reliable distributed load balancing scheme for grid networks. PhD thesis, Liverpool John Moores University.

Amblee, N., and T. Bui. 2007. The impact of electronic-word-of-mouth on digital microproducts: An empirical investigation of amazon shorts. 15th European conference on Information Systems, Switzerland.

Antweiler, W., and M.Z. Frank. 2004. Is all that talk just noise? The information content of internet stock message boards. The Journal of Finance 59: 1259-95.

Barabási, A.L. 2001. The physics of the web. Physics World 14: 33-8.

Bowman, D., and D. Narayandas. 2001. Managing customer-initiated contacts with manufacturers: The impact on share of category requirements and word-of-mouth behaviour. Journal of Marketing Research 38: 291-7.

Breschi, S., L. Cassi, F. Malerba, and N.S. Vonortas. 2009. Networked research: European policy intervention in ICTs. Technology Analysis \& Strategic Management 21: 833-57.

Chatterjee, P. 2001. Online reviews: Do consumers use them? In Advances in consumer research, 129-34. Provo, UT: Association for Consumer Research.

Chen, P.S., S. Wu, and J. Yoon. 2004. The impact of online recommendations and consumer feedback on sales. 25th Interntional conference on Information Systems, Washington, DC, 711-24.

Chen, P.Y., S. Dhanasobhon, and M.D. Smith. 2008. All reviews are not created equal: The disaggregate impact of reviews and reviewers at Amazon.com. Heinz Research. Paper 55.

Cheung, C.M.K., M.K.O. Lee, and N. Rabjohn. 2008. The impact of electronic word-of-mouth. The adoption of online opinions in online customer communities. Internet Research 18: 229-47.

Cheung, C.M.K., C. Luo, C. Sia, and H. Chen. 2009. Credibility of electronic word-of-mouth: Informational and normative determinants of on-line consumer recommendations, International Journal of Electronic Commerce 13: 9-38.

Cheung, C.M.K., and D.R. Thadani. 2012. The impact of electronic word-of-mouth communication: A literature analysis and integrative model. Decision Support Systems 54: 461-70.

Chevalier, J.A., and D. Mayzlin. 2006. The effect of word of mouth on sales: Online book reviews. Journal of Marketing Research 43, no. 3: 345-54.

Chintagunta, P.K., S. Gopinath, and S. Venkataraman. 2010. The effects of online user reviews on movie box office performance: Accounting for sequential rollout and aggregation across local markets. Marketing Science 29, no. 5: 944-57.

Cho, Y., J. Hwang, and D. Lee. 2012. Identification of effective opinion leaders in the diffusion of technological innovation: A social network approach. Technological Forecasting \& Social Change 79: 97-106.

Clauset, A., C.R. Shalizi, and M.E.J. Newman. 2007. Power-law distributions in empirical data. SIAM Review 51: 661-703.

De Bruyn, A., and G.L. Lilien. 2008. A multi-stage model of word-of-mouth influence through viral marketing. International Journal of Research in Marketing 25: 151-63.

Dellarocas, C. 2003. The digitization of word of mouth: Promise and challenges of online feedback mechanisms. Management Science 49, no. 10: 1407-24.

Dellarocas, C., N. Awad, and M. Zhang. 2005. Using online ratings as a proxy of word-of-mouth in motion picture revenue forecasting. Working Paper, Smith School of Business, University of Maryland, College Park.

Dellarocas, C., X. Zhang, and N.F. Awad. 2007. Exploring the value of online product reviews in forecasting sales: The case of motion pictures. Journal of Interactive Marketing 21, no. 4: 23-45.

Dhar, V., and E.A. Chang. 2009. Does chatter matter? The impact of user-generated content on music sales. Journal of Interactive Marketing 23, no. 4: 300-7.

Dobele, A., A. Lindgreen, M. Beverland, J. Vanhamme, and R. van Wijk. 2007. Why pass on viral messages? Why pass on viral messages? Business Horizons 50: 291-304.

Duan, W., B. Gu, and A.B. Whinston. 2008. Do online reviews matter? - An empirical investigation of panel data. Decision Support Systems 45, no. 4: 1007-16. 
Ferguson, J.L., and E.J. Johnston. 2011. Customer response to dissatisfaction: A synthesis of literature and conceptual framework. Industrial Marketing Management 40: 118-27.

Forman, C., A. Ghose, and B. Wiesenfeld. 2008. Examining the Relationship between reviews and sales: The role of reviewer identity disclosure in electronic markets. Information Systems Research 19, no. 3: 291-313.

Freemann, L.C. 1977. A set of measures of centrality based on betweenness. Sociometry 40: 35-41.

Gamon, M., A. Aue, S. Corston-Oliver, and E. Ringger. 2005. Pulse: Mining customer opinions from free text. Advances in Intelligent Data Analysis 6: 121-32.

Gu, B., Q. Tang, and A.B. Whinston. 2013. The influence of online word-of-mouth on long tail formation. Decision Support Systems 56: 474-81.

Hennig-Thurau, T., K.P. Gwinner, G. Walsh, and D.D. Gremler. 2004. Electronic word-of-mouth via consumer-opinion platforms: What motivates consumers to articulate themselves on the Internet? Journal of Interactive Marketing 18, no. 1: $38-52$.

Hennig-Thurau, T., and G. Walsh. 2003. Electronic word-of-mouth: Motives for and consequences of reading customer articulations on the Internet. International Journal of Electronic Commerce 8, no. 2: 51-74.

Hu, N., L. Liu, and J. J. Zhang. 2008. Do online reviews affect product sales? The role of reviewer characteristics and temporal effects. Information Technology and Management 9, no. 3: 201-14.

Jeong, E., and S. Jang. 2011. Restaurant experiences triggering positive electronic word-of-mouth motivations. International Journal of Hospitality Management 30: 356-66.

Jeppesen, L.B., and M.J. Molin. 2003. Consumers as co-developers: Learning and innovation outside the firm. Technology Analysis \& Strategic Management 15, no. 3: 363-83.

Keller, E., and J. Berry. 2003. The influentials. New York: Free Press.

Khammash, M., and G.H. Griffiths. 2011. 'Arrivederci CIAO.com, Buongiorno Bing.com' - Electronic word-of-mouth, antecedences and consequences. International Journal of Information Management 31: 82-7.

Kim, Y.S., and V.L. Tran. 2013. Assessing the ripple effects of online opinion leaders with trust and distrust metrics. Expert Systems with Applications 40: 3500-11.

Kiss, C., and M. Bichler. 2008. Identification of influencers - Measuring influence in customer networks. Decision Support Systems 46: 233-53.

Ku, Y.C., C.P. Wei, and H.W. Hsiao. 2012. To whom should I listen? Finding reputable reviewers in opinion-sharing communities. Decision Support Systems 53: 534-42.

Lee, T.Y. 2007. Needs-based analysis of online customer reviews. 9th international conference on Electronic Commerce, August 19-22, in Minneapolis, MN, USA.

Lee, M.K.O., C.M.K. Cheung, K.H. Lim, and C.L. Sia. 2006. Understanding customer knowledge sharing in web-based discussion boards: An exploratory study. Internet Research 16, no. 3: 289-303.

Lee, J., D.H. Park, and I. Han. 2008. The effect of negative online consumer reviews on product attitude: An information processing view. Electronic Commerce Research and Applications 7, no. 3: 341-52.

Lee, J., D.H. Park, and I. Han. 2011. The different effects of online consumer reviews on consumers' purchase intentions depending on trust in online shopping malls. An advertising perspective. Internet Research 21, no. 2: 187-206.

Liu, Y. 2006. Word of mouth for movies: Its dynamics and impact on box office revenue. Journal of Marketing 70, no. 3: 74-89.

Martínez-Torres, M.R. 2013. Application of evolutionary computation techniques for the identification of innovators in open innovation communities. Expert Systems with Applications 40, no. 7: 2503-10.

Martínez-Torres, M.R. 2014. Analysis of open innovation communities from the perspective of social network analysis. Technology Analysis \& Strategic Management 26, no. 4: 435-51. doi:10.1080/09537325.2013.851378

Martínez-Torres, M.R., and C. Díaz-Fernandez. 2013. Current issues and research trends on open source software communities. Technology Analysis \& Strategic Management 26, no. 1: 55-68.

Martínez-Torres, M.R., S. Toral, F. Barrero, and F. Cortés. 2010. The role of Internet in the development of Future Software Projects. Internet Research 20, no. 1: 72-86.

Newman, M.E.J. 2003. The structure and function of complex networks. SIAM Review 45, no. 2: 167-256.

Pan, L.Y., and J.S. Chiou. 2011. How much can you trust online information? Cues for perceived trustworthiness of consumer-generated online information. Journal of Interactive Marketing 25: 67-74.

Park, C., and T.M. Lee. 2009. Information direction, website reputation and eWOM effect: A moderating role of product type. Journal of Business Research 62, no. 1: 61-7.

Park, D.H., J. Lee, and I. Han. 2007. The effect of on-line consumer reviews on consumer purchasing intention: The moderating role of involvement. International Journal of Electronic Commerce 11, no. 4: 125-48. 
Phelps, J.E., R. Lewis, L. Mobilio, D. Perry, and N. Raman. 2004. Viral marketing or electronic word-of-mouth advertising: Examining consumer responses and motivations to pass along email. Journal of Advertising Research 44, no. 4: 333-48.

Scott, J. 2000. Social network analysis: A handbook. London: Sage.

Smith, A., E. Fischer, and C. Yongjian. 2012. How much can you trust online information? Cues for perceived trustworthiness of consumer-generated online information. Journal of Interactive Marketing 25: 67-74.

Sowe, S., I. Stamelos, and L. Angelis. 2006. Identifying knowledge brokers that yield software engineering knowledge in OSS projects. Information and Software Technology 48, no. 11: 1025-33.

Steffes, E.M., and L.E. Burgee. 2009. Social ties and online word of mouth. Internet Research 19, no. 1: 42-59.

Toral, S.L., M.R. Martínez-Torres, and F. Barrero. 2010. Modelling mailing list behaviour in open source projects: The case of ARM embedded Linux. Journal of Universal Computer Science 15, no. 3: 648-64.

Trusov, M., R.E. Bucklin, and K. Pauwels. 2009. Effects of word-of-mouth versus traditional marketing: Findings from an internet social networking site. Journal of Marketing 73, no. 5: 90-102.

Tumarkin, R., and R.F. Whitelaw. 2001. News or noise? Internet postings and stock prices. Financial Analysts Journal 57, no. 3: 41-51.

Vilpponen, A., S. Winter, and S. Sundqvist. 2006. Electronic word-of-mouth in online environments: Exploring referral networks structure and adoption behavior. Journal of Interactive Advertising 6, no. 2: 63-77.

Wassermann, S., and K. Faust. 1994. Social network analysis: Methods and applications. Cambridge: Cambridge University Press.

Wei, C.P., Y.M. Chen, C.S. Yang, and C. Yang. 2010. Understanding what concerns consumers: A semantic approach to product feature extraction from consumer reviews. Journal of Information Systems and E-Business Management 8, no. 2: 149-67.

Westbrook, R.A. 1987. Product/consumption-based affective responses and post purchase processes. Journal of Marketing Research 24, no. 3: 258-70.

Yang, J., and E. Mai. 2010. Experiential goods with network externalities effects: An empirical study of online rating system. Journal of Business Research 63: 1050-7. 